\title{
HISTORIA DE ABORTO INDUCIDO Y RESULTADOS PERINATALES ADVERSOS
}

\author{
EFFECT OF INDUCED ABORTIONS ON ADVERSE PERINATAL OUTCOMES
}

\author{
Eduardo Cuestas'.
}

El parto prematuro es un problema sanitario de suma importancia en nuestro país. A pesar de los avances recientes en la atención médica, continúa siendo la causa principal de morbilidad y mortalidad neonatales en todo el mundo. Se ha demostrado que el riesgo de desarrollar enfermedades neonatales aumenta con la disminución de la edad gestacional. Las complicaciones a corto plazo del nacimiento prematuro, como el síndrome de dificultad respiratoria, la enterocolitis necrotizante, la hemorragia intraventricular y la sepsis, son todas enfermedades graves que representan un serio desafío para las unidades de cuidados intensivos neonatales. El parto prematuro también se asocia con serias consecuencias a largo plazo, vinculadas especialmente a discapacidades del desarrollo neurológico, como la parálisis cerebral y afecciones médicas crónicas, como la displasia broncopulmonar, entre muchas otras y enfermedades cardiometabólicas en la vida adulta.

La tasa de nacimientos prematuros ha ido en aumento, en 2017 en Argentina se estimó en aproximadamente $8 \%$ de todos los nacimientos. En varios estudios se ha demostrado una asociación entre el aborto inducido y la prematuridad en embarazos posteriores. Esta relación es muy relevante para nuestro país debido al alto número de abortos realizados anualmente. En 2017, se calcula que se realizaron entre 370.000 y 520.000 abortos en Argentina, con 680.000 nacimientos en ese mismo año.

Estudios previos han examinado la relación entre el aborto inducido (médico y quirúrgico) y el parto prematuro y han sugerido que el aborto está asociado con amenaza de parto prematuro, rotura prematura de membranas y hemorragia anteparto. Sin embargo, pocos estudios han evaluado el efecto que los abortos inducidos tienen sobre la severidad de la prematuridad. Aunque el mecanismo causal del parto prematuro es en gran parte desconocido, se ha sugerido que el parto prematuro puede implicar insuficiencia cervical, infección o una combinación de ambos.

Los resultados del estudio de una cohorte de grandes proporciones efectuado recientemente, sugieren claramente que el aborto inducido previo aumenta el riesgo de tener un parto prematuro espontáneo en un embarazo posterior y que este vínculo se fortalece en los partos extremadamente prematuros.

El nacimiento de bebés prematuros representa una gran carga para la sociedad en todo el mundo, demandando un enorme esfuerzo para cuidar, atender, contener y tratar, tanto la morbilidad a corto plazo (incluyendo síndrome de dificultad respiratoria, enterocolitis necrosante y hemorragia intraventricular), como a largo plazo, incluyendo las demandas de educación especial asociadas con parálisis cerebral, retraso mental, discapacidad visual y pérdida de audición.

Respecto a la asociación entre aborto inducido previo y el parto prematuro se han propuesto hipótesis de componentes infecciosos y mecánicos. Para tratar de determinarlo, diferentes estudios han revisado estas ideas y han propuesto mecanismos específicos (como infección intraamniótica, hemorragia anteparto e incompetencia cervical) que conducen a un embarazo con parto prematuro en mujeres con historia de un aborto inducido previo. La infección intraamniótica es la vía que ha sido más estudiada. En un estudio de casos y controles, Krohn et al encontraron una fuerte asociación entre la infección intraamniótica y el antecedente de una terminación electiva del embarazo. Aunque el mecanismo para la asociación es desconocido, este estudio sugiere un vínculo con una complicación de embarazo bien conocida (la corioamnionitis) pero no especifica la fisiopatología y la cronología del proceso de infección para probar el vínculo causal. En cambio varios estudios realizados en la década pasada han comprobado la hipótesis del daño uterino, sea este morfológico o funcional.

Los procedimientos de interrupción del embarazo, ahora se realizan a una edad gestacional más temprana, la mayoría de las veces utilizando aspiración en lugar de legrado, y el uso de agentes análogos de la $\mathrm{PGE}_{1}$ como el misoprostol y antiprogestágenos como la mifepristona, está cada vez más extendido y accesible. Estas técnicas más nuevas pueden disminuir la gravedad del trauma uterino. Un estudio de cohortes danés reciente mostró una tasa de lesiones cervicales de 0,89 por 1000 mujeres en abortos farmacológicos. Sin embargo, el daño cervical, ya sea microscópico o macroscópico, podría resultar en un debilitamiento permanente del cuello uterino. No es improbable que este cambio mecánico en el cuello uterino pueda conducir a una mayor predisposición a la infección ascendente del tracto genital o a la insuficiencia cervical que conduce a la prematuridad. El hecho de que la asociación entre aborto y parto prematuro haya mostrado un vínculo más fuerte con la edad gestacional temprana sugiere que es más

\footnotetext{
${ }^{1}$ Editor Jefe
}

DOI: 10.31053/1853-0605.v75.n1.20217 
probable un problema mecánico, como se ve típicamente en casos de insuficiencia cervical o incompetencia (en el cual el parto ocurre más comúnmente en el segundo trimestre).

Las mujeres en edad reproductiva a menudo no son conscientes de todas las posibles complicaciones a corto y largo plazo que pueden surgir de un aborto inducido; por lo tanto, se deben establecer políticas sólidas de salud pública para garantizar que haya métodos anticonceptivos efectivos disponibles para limitar la necesidad del aborto inducido en embarazos no deseados. Reducir la necesidad de interrupción del embarazo al proporcionar anticoncepción segura y efectiva para todas las mujeres que lo requieran debería considerarse como uno de los más importantes enfoques para la reducción de las tasas de prematurez.

Eduardo Cuestas Editor Jefe 